\title{
Learning Logs: The Effect of Incorporating Write-to-Learn Assignments on Promoting Learning and Retention of Information in a Phonology Course
}

\author{
Nawal Nabih Ayoub, PhD Student \\ Department of English Language, Faculty of Human Sciences, \\ Beirut Arab University (Beirut Campus), Lebanon
}

URL:http://dx.doi.org/10.19044/esj.2020.v16n13p80

\begin{abstract}
This paper examines the role of learning logs in promoting learning, retaining information, and improving test scores through writing in a phonology course. At first, this study aims at showing how the difficulties of phonology concepts and pronunciation teaching for university students create problems in content comprehension. The preliminary study used an experimental design, a true experiment, to examine the data and validate the results of using different learning logs as one technique of the Write-to-Learn (WTL) approach which aims at improving the students' learning outcomes. A total of 30 students sharing a similar social and educational background were randomly assigned into experimental and control groups. The work group of the present research consists of 15 students who were given several learning log assignments during the Summer semester while the control group, also made up of 15 students, was given the course without any log assignments. A pre-post-test was conducted to both groups in order to find out whether both groups' knowledge about phonology and pronunciation teaching developed throughout the semester. Four tests were administered to both groups in a period of five weeks in the semester. The findings of the study indicate that EFL students in the experimental group at LIU (Lebanese International University) outperformed their counterparts in the control group concerning the retention of the key conceptual knowledge, and the content comprehension of course concepts. A statistical analysis of exam scores on learning log indicator variables shows that learning logs increase content comprehension and improve test scores.
\end{abstract}

Keywords: Write-to-learn; writing across the curriculum; learning logs; segmental features; supra-segmental features 


\section{Introduction}

Teaching phonology and pronunciation is vital for effective oral communication. According to Hişmanoğlu (2006), both phonology and pronunciation are considered as chief ingredients for developing communicative competence. According to the related literature, intelligible pronunciation is highly essential to cultivate communicative competence (Roberston,2003; Morley,1991). In a phonology curriculum, university students are trained on how to teach segmental and supra-segmental features. In language, segmental features are the individual sounds that could be broken down and applied individually. They are also called phonemes which include consonant and vowel sounds (Meshach,2017). Research has demonstrated that intelligible segmental information has an impact on communication (Morgan,2019). Supra-segmental features, also called prosodic features embrace language stress, connected speech, pitch, intonation, rhythm, loudness, and duration. These features are not bounded to single sounds; nonetheless, they often extend over phrases, words, or syllables (Meshach,2017). Teaching phonology concepts to university students means providing explicit instruction on pronunciation features and teaching them strategies to help them transfer that knowledge to their learners subsequently. Such learning requires an in-depth investigation of phonology concepts. Sometimes, students face difficulties in understanding these concepts and in retaining that information. According to the related literature, writing assists and increases the learning of concepts across the curriculum. Bangert-Drowns, Hurley, \& Wilkinson (2004) pointed out that when students write about what they are learning, they apply self-regulation activities and meta-cognitive skills. Besides, when students write about the content being learned in class, they practice a complex process that needs to link their thinking to the content learned. As a result, students become capable of planning, evaluating, and using the strategies to organize their knowledge.

Writing activities, known as "write-to-learn" activities have a great influence on students' learning. They can help them learn content at school and university. McLeod (2000) affirmed that write-to-learn assignments are considered as one component of Writing Across the Curriculum (WAC) which is an educational movement designed to integrate writing assignments through students' courses. Anson (2007) and Emig (1977) define write-to-learn assignments as low-stakes writing pieces that facilitate learning, permit exploring new concepts and develop a deeper understanding of a course since they are much more focused on how students explain content and phenomena, rather than on features of writing itself.

A learning log or journal is one form of write-to-learn assignments that have been used for several decades in a variety of learning contexts such as psychology (Cisero, 2006), business (Pavlovich, Collins \& Jones, 2007), 
education (Blaschke \& Brindley, 2010), and foreign language learning and teaching (Bailey, 1991). Recently, Wu David (2019) has noted that a learning log contains a record of ones' experiences, feelings, thoughts, and reflections. More importantly, he added that a learning log contains a conclusion in which the learner writes about how and what he has learned indicating the relevancy of the content and the possibility of using the new information in the future.

Thus, the purpose of the present research paper is to investigate the efficacy of write-to-learn assignments, mainly learning logs, in order to enhance content comprehension and learning of phonology concepts. It is also hoped that this study would give insights for phonology educators to incorporate WTL in their courses.

\section{Statement of the Problem}

Many students at the Lebanese International University (LIU) in southern campuses are able to understand pronunciation and phonology concepts, but most of them face problems in effectively communicating these ideas on paper during exams. Many ENG 400 (Phonology) students at LIU Saida campus do not comprehend important details or even cannot go beyond what is discussed in the book. In addition, most of the instructors who teach this course complain about the inability of many students to achieve the intended learning outcomes of the course. For this reason, the present study addresses this issue to demonstrate how the students' writing samples allow them to understand phonology concepts and comprehend them through writing while being creative and reflective.

\section{Literature Review}

A knowledge of English pronunciation as an area of study is priceless. For second language learners, pronunciation is the gateway to spoken intelligibility since it has close ties to the social meaning within language. Reed \& Levis (2019) pointed out that pronunciation helps in distinguishing dialects, informal and formal registers of speech. They stated that it is also considered essential since it could determine the social standing within speech networks. More importantly, they added that English pronunciation is important not only to learners but also to teachers. In a study employed with 19 English language teachers in New Zealand, Couper (2016) examined the participants' perceptions about teaching pronunciation and found out that there was a lack of initial training and knowledge of phonology. This lack leads to uncertainty about what should be exactly taught and how.

A lot of studies have been conducted on the influence of learning logs on learning and retention of information, yet insufficient research is found on the influence of these logs on promoting learning in phonology courses. A study conducted on 76 students majoring in languages and translation at a 
Spanish university, Bakieva and Litzler (2017) revealed that the majority of the students opted to complete a daily log. In terms of the learners' autonomy, students were generally positive about the activity and admitted its effectiveness.

In another study, Grimm (2015) introduced the learning logs in an introductory financial accounting course and emphasized the positive effects as reported by students. She contended that learners perceived the learning logs as advantageous. She added that a regression analysis of exam scores on learning log indicator variables showed that learning logs intensify content comprehension.

Exploring the power of learning logs in a phonology course might reveal individual differences in students' learning and comprehension and thus would encourage EFL instructors to take into consideration the students' preferences and adopt write-to-learn strategies, such as learning logs. The present study, therefore, aims to identify the impact of learning logs on content comprehension in phonology. With respect to this aim, the present study raises the following research question:

To what extent does the use of learning logs as a form of Write-toLearn approach affect positively on students' learning outcomes in phonology?

\section{Methodology}

This study used an experimental design to find out data, analyze and verify the results of using learning logs to improve students' learning outcomes in a phonology course. The study was conducted across the 2018-2019 Summer semester. 15 students were manipulated into the experimental group in which they had to complete learning logs and email them to the instructor to get feedback before sitting for their tests. Another group of 15 students, the control group, had to sit for their exams without preparing any logs.

\section{Participants}

The work group of the present research matches on common measures including gender, age, years of language study, and language(s) spoken at home. It consists of 30 female and male undergraduate EFL students enrolling in the same academic year 2018-2019 at LIU, a private Lebanese university in Southern Lebanon. The participants' ages range from 19 to 22 years. Most of them have studied EFL since kindergarten, as per Lebanese curriculum requirements, yet their first language is Arabic.

The participants are second and third year EFL students majoring in TESL (Teaching English as a Second Language) or CHED (Childhood Education), and they registered in the phonology course (ENG400) to become aware of and develop phonological concepts. During summer 2018-2019, 30 
students enrolled in the course, ENG400, sharing a similar social and educational background. Both the control group (15 students) and the experimental group (15 students) were supervised by the researcher herself for five consecutive weeks, 4 days in a week from Monday to Thursday, and for 2 hours per day. The time and duration were set as requested by the university system.

The experimental group (15 students) studied phonology concepts and prepared learning logs throughout the semester while the control group (15 students) learned the same phonology concepts without doing any writing or preparing any logs.

\section{Design of the study}

In this study, the quantitative method is employed since the scores of the tests of the two groups will be compared. For the quantification of data, Mackey and Gass (2005) pointed out that measurements, scores, frequencies, and ratings have to be carried. Brown and Rodgers (2002) added that those sustained measures that turn into numbers and statistics have to be valid, reliable, and objective. To achieve this, the quantitative data in this experimental research will be collected through test scores, the participants' scores, both experimental and control groups, in the 4 tests administered over summer 2018-2019, in addition to a pre-test and a post-test for the two groups.

\section{Instruments of Data Collection}

The instruments in this study are students' tests in both the experimental and the control groups before and after the experiment in addition to 4 other tests held throughout the semester.

\subsection{The Pre-test and the Post-test: Dependent Tests}

A pre-test and a post-test were held to both groups. The need for the pre-test is obvious because if pre-existing knowledge is not established at the beginning, it is impossible to know whether the post-test knowledge is a new acquisition or simply knowledge that was in place before the study began. The post-test, held at the end of the semester, is identical to the pre-test in content and format, and it aims to show whether students developed their understanding of phonology concepts and whether there is better development with log application. (See Appendix A).

\subsection{The Four Tests: Independent Tests}

The two groups had to undergo four tests. Each test was held at the beginning of a new week when the learning log was checked and assessed for the experimental group. Test 1 reinforced the features, physiology and articulation of pronunciation, phonemic transcription, phonology and 
phonetics (See Appendix B). Test 2 focused on the approaches, reasons, problems, and techniques for teaching pronunciation as well as on pronunciation lesson plan (See Appendix C). Test 3 focused on phonemic transcription and English orthography (See Appendix D), and Test 4 examined students' understanding of intonation, word, and sentence stress, connected speech, and phonemic transcription (See Appendix E).

The average of the exams' scores of students who completed the learning logs were compared with the average of exams' scores of the students who did not complete the learning logs in order to find out the effect of the treatment and to show how these logs influence students' comprehension and performance.

\section{4. $\quad$ Procedures}

The major resource or reference for ENG 400 is a text-book called How to Teach Pronunciation, Longman by Kelly, G. (2000). The general aim of ENG 400 is to introduce students to the conceptual framework of phonetics and phonology along with practical ideas and skills for their future teaching.

The purpose of this study is to investigate the effectiveness of learning logs in promoting learning in a phonology course. For this, 30 learners participated in this study. All participants were involved from the beginning until the end of the study. The participants were classified into control and experimental groups according to their interests.

The study took place during the Summer semester 2018-2019 which started on July $1^{\text {st }}$ and ended on July $31^{\text {st }}$. At the onset of the semester, a pretest was conducted to both groups to check their knowledge of phonology and pronunciation concepts.

During the procedure, both the control and experimental groups were exposed to in-class routine lectures and exercises. However, at the end of the first teaching week (which lasted 4 days), students in the experimental group were emailed the first learning log to work on. Most students were willing to respond, and at the weekend, they emailed their work to their instructor to get feedback which they believed was effective and constructive. They also believed that in that way, they were preparing for the coming test. The control group, on the other hand, was not asked to work on the logs, but the students were asked to prepare for the coming test which was common with the experimental group and which was held at the beginning of the second week.

The same procedures were repeated 3 more times, and students in the experimental group worked on three other logs and emailed them to the instructor to receive feedback. Students in the two groups had to sit for 3 more tests. The total was 4 tests that were analyzed to find out whether the learning logs prepared by students in the experimental group added to their 
comprehension and retention of information and helped them improve their test scores.

Finally, the post-test which had the same content and format as the pre-test was conducted for both groups in order to find out how students' knowledge about phonology and pronunciation concepts developed at the end of the course.

\section{Description of the Learning Log Assignments}

In each assignment, the learning log requires students to interpret and explain phonology concepts to certain audiences. Designed by the instructor herself, the formats of the learning $\log s$ are varied, with some structured as reflective papers, others as letters, and others as PowerPoint presentations. Anson (2007) believes that altering the format and audience of WTL assignments necessitates students to translate concepts in their own words rather than simply parroting back the textbook. Each learning log assignment and its related learning objective are discussed below to illustrate the format of the different WTL assignments.

\section{Log 1: The Description of Speech}

Objective: The goal of this assignment is to reinforce the features, physiology, and articulation of pronunciation, phonemic transcription, phonology, and phonetics.

Assignment: Pretend that one of your relatives who is registered in your class has been absent since the beginning of the semester, and your instructor has almost covered chapter 1 which your relative knows nothing about.

Send them an informal letter explaining to them the subparts of chapter 1 (features of pronunciation, physiology of pronunciation, articulation of phonemes, phonemic transcription, phonetics, and phonology). Remember to include your research about the required topics. You can follow any writing style since it is an informal letter. Remember that your purpose is to explain.

\section{Log 2: Teaching Pronunciation}

Objective: The goal of this assignment is to understand the reasons of teaching pronunciation, approaches, problems, and techniques, and to prepare a pronunciation lesson plan.

Assignment: Write a three-page reflection paper on the approaches and techniques in teaching pronunciation. Also, explain two interesting activities from chapter 2 which you would like to adopt when teaching a pronunciation lesson. Include the parts of a pronunciation lesson plan. 
Log 4: Intonation, word and sentence stress, connected speech, phonemic transcription Objective: The goal of this assignment is to reinforce aspects of connected speech, intonation, word and sentence stress, and to practice phonemic transcription and English orthography.

Assignment: You are asked to deliver a presentation in class in preparation for the final exam. The PowerPoint presentation will include the topics in the charts below. Fill in the charts with the suitable information, and then organize your work into different slides.

\section{Log 3: Phonemic Transcription and English Orthography}

Objective: The goal of this assignment is to practice phonemic transcription and English orthography.

Assignment: Your classmates have chosen a few transcription exercises for you to practice working on. Please, practice writing in English and transcribing these exercises and bring them to class for peer correction. Also, write a short paragraph on your own and transcribe it yourself. At last, email your work to your instructor to get feedback.

A. Write the following passage into English.

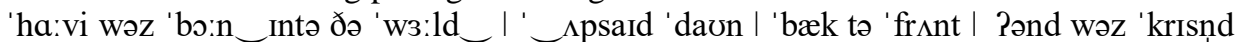

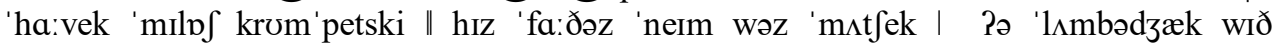

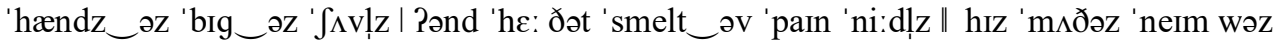
lilı'a:nə | Pə 'wıəri 'wumən wıð 'led_in hə 'veinz frəm 'w3:kı_ In_o 'main \| $\int i$

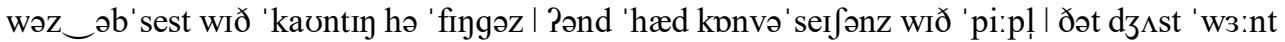

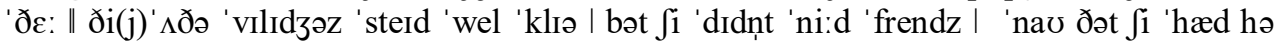
'mirək1 \|

B. Transcribe the following extract.

For more information, this disaster caused severe destruction which was only solved after intense effort. Leaders of many countries and intergovernmental organizations, including the United Nations and European Union, responded to the earthquake and sent messages of condolence to the government and people of Chile over the loss of lives and properties.

C. My own paragraph

Log 4: Intonation, word and sentence stress, connected speech, phonemic transcription Objective: The goal of this assignment is to reinforce aspects of connected speech, intonation, word and sentence stress, and to practice phonemic transcription and English orthography.

Assignment: You are asked to deliver a presentation in class in preparation for the final exam. The PowerPoint presentation will include the topics in the charts below. Fill in the charts with the suitable information, and then organize your work into different slides.

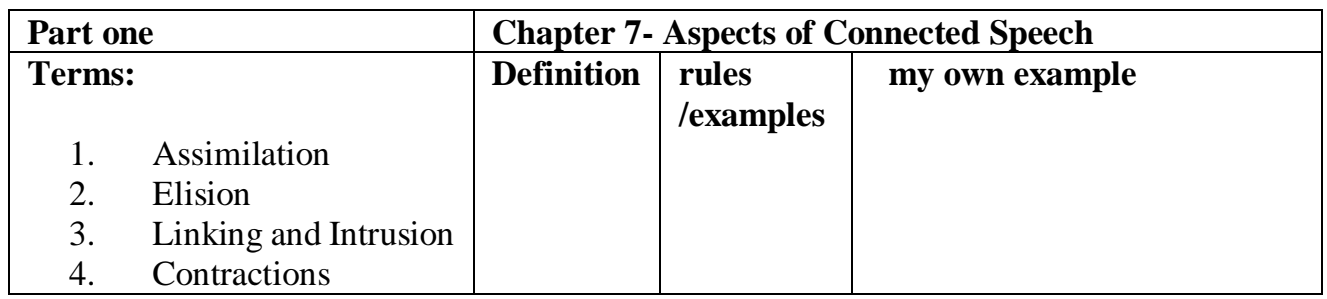




\section{Part Two: Chapter 5 Word and sentence stress}

\section{A. Example: They are surprising neighbors.}

When stress falls on surprising, it acts like an adjective to describe the neighbors. However, when stress falls on neighbors, it means that the act falls on the neighbors not on somebody else; so we are surprising the neighbors not the strangers or other people.

B. Another example: They are motivating people.

\section{Explain:}

C. My own example:

Explain:

D. My summary and reflection:

\begin{tabular}{|l|l|l|}
\hline Part Three: Chapter 6: & & \\
Intonation & \\
• My summary and & & \\
reflection
\end{tabular}

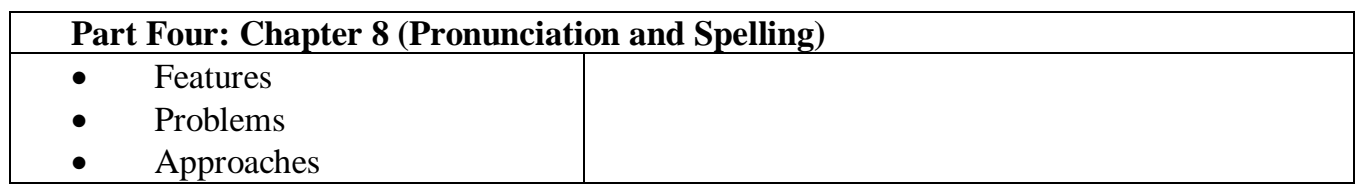

\begin{tabular}{|c|c|c|c|}
\hline \multicolumn{4}{|c|}{ Part Five: Phonemic Table } \\
\hline 1.Consonants: & $\begin{array}{l}\text { Transcribed } \\
\text { symbol }\end{array}$ & Example 1 & Example 2 \\
\hline $\begin{array}{l}\text { 2.Single vowels } \\
\text { 3. Diphthongs } \\
\text { 4. Triphthongs } \\
\text { 5.My own } \\
\text { paragraph and its } \\
\text { transcription }\end{array}$ & & & \\
\hline
\end{tabular}

\section{Data Analysis}

Data distributions were analyzed. Also, descriptive and inferential statistics were applied through graphs, independent and paired students' t-test for the averages of students' pre-post-tests as well as the averages of the four tests for both groups, the control and the experimental.

Test for significance was one and two-tailed and all analyses adopted an alpha-risk value of 5\%. All statistical analyses were performed with SPSS software. 


\section{Comparison of students' pre-tests and post-tests for Control and Experimental Groups}

A total of 30 students were enrolled in this study. Students' pre-test and post-test scores in the control and the experimental groups are detailed in figures 1 and 2 .

In brief, figures $1 \& 2$ show a descriptive analysis of students' pre-test and post-test scores. With reference to figure 1 of the control group that did not prepare learning logs, it is concluded that students' grades improved but many of their grades increased by 1 grade only.

While in figure 2, most of the students' grades in the experimental group that prepared the learning logs increased by 2 grades or more. This allows us to conclude that the Write-to-Learn approach, through learning logs, improved the scores of the students in comparison to the conventional approach.

Figure 1

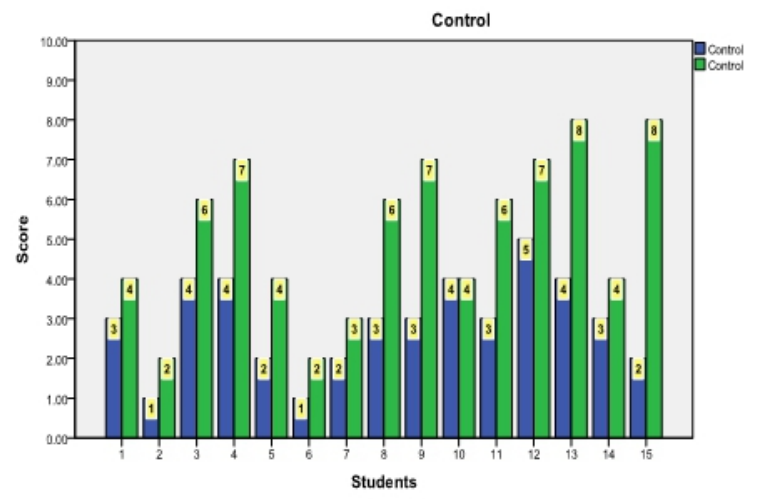

Figure 2

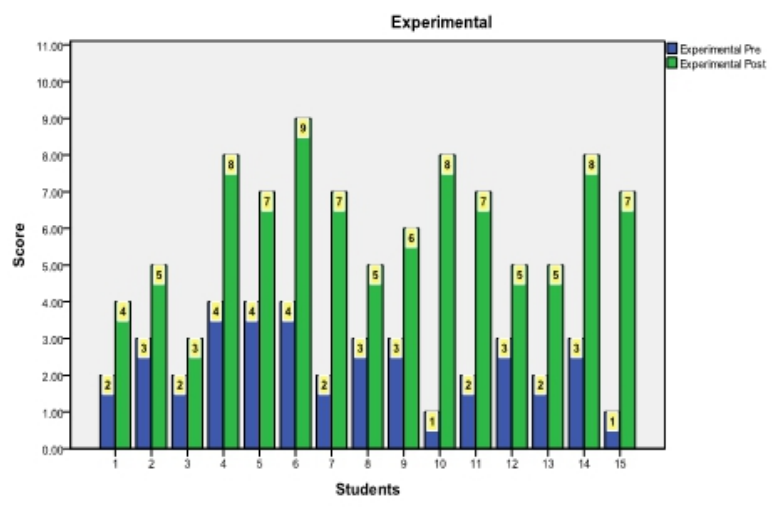

Assessing Normality of mean differences for pre-test and post-test scores (Control and Experimental groups).

In table 1, the p-values of Kolmogorov-Smirnov and Shapiro-Wilk tests are greater than the alpha-risk value (5\%). Thus, we can conclude that the population means differences for the control (CTL) and experimental (EXP) groups are normally distributed.

Table 1: Tests of Normality

\begin{tabular}{|l|l|l|}
\hline Variables & Kolmogorov-Smirnov (P-value) & Shapiro-Wilk (P-value) \\
\hline CTL & 0.16 & 0.16 \\
\hline EXP & 0.20 & 0.28 \\
\hline
\end{tabular}

Description of the dependent test analysis for the difference between the pre-test and the post-test of the control and experimental groups 
In table 2, the students' pre-test and post-test grades of the control group were compared, and they showed an improvement, so we conclude that the average of the class (2.93 vs. 5.20) increased without the log. Also, when the pre-test and the post-test grades of the experimental group were compared, it was concluded that they too improved, and the average of the class increased (2.60 vs. 6.27). Thus, after comparing both tests, we can find that we have an increase, and that can be emphasized by checking the p-values for both groups where they are less than the alpha-risk value (5\%). However, the increase is more with the log application. This can be evident when we compare the mean scores difference of the two groups. The difference in the mean scores of the experimental group is (3.67) which is greater than that of the control group (2.27) that did not undergo any treatment. Also, we can emphasize this by analyzing the t-statistics for the experimental group (8.07) which is higher than that of the control group (5.56). This means that there is more increase in the grades of the experimental group and that the difference between the grades is higher.

Table 2: Paired Samples Statistics

\begin{tabular}{|c|c|c|c|c|}
\hline Variables (Pair) & Mean & $\begin{array}{c}\text { Mean } \\
\text { Difference }\end{array}$ & t-statistics & P-value \\
\cline { 1 - 2 } CTLPRE & 2.93 & 2.27 & 5.56 & 0.00 \\
\cline { 1 - 2 } CTLPOST & 5.20 & 3.67 & 8.07 & 0.00 \\
\hline EXPPRE & 2.60 & 6.27 & & \\
\hline
\end{tabular}

Comparison of students' exams performance

Analyzing exam performance, a proxy for content comprehension is significant to assess students' learning. The literature of WTL suggests that writing assignments increase students' comprehension of concepts (Stock 1986). This paper tests this assertion in the phonology education context by testing the following hypothesis:

H1: Learning log assignments can be associated with higher student comprehension of phonology concepts and better learning outcomes.

A comparison of exams' average of students who completed the four learning logs with the exams' average of the students who did not complete the logs is one way to test how learning logs influence students' comprehension of phonology concepts.

Four tests were conducted throughout the semester, and the exams' averages of the two groups have been recorded.

Table 3 shows that the grades for both groups are normally distributed since the p-values of Kolmogorov-Smirnov and Shapiro-Wilk tests are greater than the alpha-risk value $(5 \%)$. 
Table 3: Tests of Normality

\begin{tabular}{|c|c|c|}
\hline Variables & Kolmogorov-Smirnov (P-value) & Shapiro-Wilk (P-value) \\
\hline CTL & 0.20 & 0.22 \\
\hline EXP & 0.20 & 0.55 \\
\hline
\end{tabular}

Moreover, as shown in table 4 below, the mean of the tests' averages for the control sample (64.85) is lower than the mean for the experimental one (74.12). Also, the standard deviation for the experimental group (8.81) is less than that for the control sample (16.05). This indicates that the dispersion between the grades for the experimental gets narrower and the grades are almost distributed around the class average.

Therefore, it can be concluded that with the learning log application, students in the experimental group showed significantly higher performance than their counterparts in the control group who did not prepare the learning logs.

Also, in table 4, a t-Test on unequal variances is shown. A t-Test for comparing means was applied, and it shows that the average of the population of the control group is less than the average of the population of the experimental group since the $\mathrm{p}$-value is 0.03 which is less than the alpha-risk value $(5 \%)$. Thus, we accept the claim that log application shows improvement in grades, and we can conclude that the average of the class after log application is higher than the average of the class without the log application.

Table 4: Independent Samples Statistics

\begin{tabular}{|c|c|c|c|}
\hline Variables & Mean & $\begin{array}{c}\text { Standard } \\
\text { Deviation }\end{array}$ & $\begin{array}{c}\text { P-value } \\
\text { (Equal variances not assumed) }\end{array}$ \\
\hline CTL & 64.85 & 16.05 & 0.03 \\
\hline EXP & 74.12 & 8.81 & 0.03 \\
\hline
\end{tabular}

\section{Discussion and Conclusion}

First, the pre-test and post-test scores were graphically and numerically analyzed to show and measure the mean differences between the scores of the students in the pre-test and the post-test. The purpose was to show how students in both groups developed throughout the course and to show whether there was a better improvement with the log application. After that, the four tests for each of the experimental and control groups were analyzed numerically. Their averages were tested through an independent t-test and we concluded that the experimental group showed better results.

At first, the dependent data which were gathered and analyzed quantitatively from students' pre-tests and post-tests showed that the participants in both groups improved. However, the mean difference of the experimental group (3.67) showed more improvement than the mean difference of the post-test of the students in the control group (2.27) as shown 
in table 2. Therefore, the students who prepared learning logs throughout the semester showed significantly higher performance in the post-test and consequently more comprehension of phonology concepts.

Concerning the averages of the four tests for experimental and control groups, it was concluded that the students who prepared the logs in the experimental group showed better performance than the students in the control group. As revealed in table 4, the tests' average of the control (64.85) was less than the tests' average of the experimental (74.12). This has been confirmed after having a p-value (0.03) less than the alpha-risk value and this means that the students who prepared the logs outperformed their counterparts in the control group.

Therefore, it can be concluded that learning logs closely linked to exam issues significantly increase exam scores. Eventually, the obtained results are consistent with previous researches that have asserted the positive impact of write-to-learn assignments, specifically learning logs, on promoting learning and comprehension, and retaining information.

The learning logs, one form of WTL assignments, allow students to learn about a concept through writing. The learning logs discussed in this paper show how WTL assignments can be designed to achieve the desired learning objectives.

To recommend, changing the audience of the learning log assignments from students, to instructors, and family members forces students to translate concepts into their own words and adds creativity to the assignments. Instructors can lessen the grading burden associated with WTL assignments by discussing the assignments in class and by allowing students to auto-correct their work. Also, they can use peer review, provide whole-class responses, and use a simple grading rubric. Instructors may also substitute quiz or homework assessments for WTL assessments.

The author hopes the WTL examples and strategies discussed in the article will encourage instructors to implement WTL assignments not only into their own phonology courses but also into other courses in a way to promote learning and comprehension.

\section{References:}

1. Anson, C. (2007). Warp and weft: Reflections on the art of communication weaving. In Sustaining Excellence in "Communicating Across the Curriculum': Cross-Institutional Experiences and Best Practices, edited by Kassabgy, N., and A. Elshimi, 2-18. Newcastle, U.K.: Cambridge Scholars Publishing.

2. Bailey, K. M. (1991). Diary studies of classroom language learning: The doubting game and the believing game, in Language acquisition and the second/foreign language classroom, Anthology Series 28, 
Sartono, E. (coord.), Singapore, SEAMEO Regional Language Centre, 60-102. http://eric.ed.gov/?id=ED367161 [Consulta: 24 de abril de 2015].

3. Bangert-Drowns, R. L., Hurley, M. M., \& Wilkinson, B. (2004). The effects of school-based writing-to-learn interventions on academic achievement: a meta-analysis. Review of Educational Research, 74, 29 -58. doi:10.3102/00346543074001029.

4. Blaschke, L. M. \& Brindley, J. (2010). Establishing a foundational framework for development of reflective thinking: Learning journals in the MDE. European Distance and E-Learning Network. www.eden-online.org. http //: doi=10.1.1.636.6621

5. Brown, J. D. \& Rodgers, T. S. (2002). Doing second language research. Oxford University Press. Vol. 7. Number 4. ISBN - 19437174-3

6. Cisero, C. A. (2006). Does reflective journal writing improve course performance? College Teaching, 54 (2), 231-236. https://doi.org/10.3200/CTCH.54.2.231-236

7. Couper, G. (2016). Teacher cognition of pronunciation teaching: teachers' concerns and issues. Tesol Quarterly. Wiley Online Library. https://doi.org/10.1002/tesq.354

8. Emig, J. (1977). Writing as a mode of learning. College Composition and Communication 28 (2): 122-128.

9. Grimm, S.D. (2015). Learning Logs: Incorporating writing-to-learn assignments into accounting courses. Issues in Accounting Education. American Accounting Association. Vol. 30, No. 2 DOI: 10.2308/iace509802015 pp. 79-104

10. Hişmanoğlu, M. (2006). Current perspectives on pronunciation learning and teaching. Journal of Language and Linguistic Studies, Vol 2.

11. Litzler, M.F. \& Bakieva, M. (2017). Learning logs in foreign language study: student views on their usefulness for learner autonomy. Didáctica. Lengua y literature. ISSN: 1130-0531 http://dx.doi.org/10.5209/DIDA.57130

12. Mackey, A. \& Gass, S. (2005). Second language research: Methodology and design. New York, NY: Routlege

13. McLeod, S. (2000). Writing across the curriculum: An introduction. In Writing Across the Curriculum: A Guide to Developing Programs, edited by McLeod, S. H., and M. Soven, 1-8. (Originally published in print in 1992). Newbury Park, CA: Sage Publications.

Meshach, T. (2017). Segmental and Suprasegmental Phonemes: Chapter 1. https://www.booksie.com $>$ 509037-segmental-andsuprasegmental-phone... 
15. Morgan, S. D. (2019). Segmental and suprasegmental communicative information: Speech versus emotion recognition thresholds. The Journal of the Acoustical Society of America 145, 1912. https://doi.org/10.1121/1.5101940

16. Pavlovic, K., Collins, E. \& Jones, G. (2007). Developing students' skills in reflective practice: Design and Assessment. Journal of Management Education, 33 (1), 37-58. doi: http:// $10.1177 / 1052562907307640$

17. Reed, M. \& Levis, J. (2015). The Handbook of English Pronunciation. Wiley Blackwell. https://doi:10.1002/9781118346952

18. Robertson, P. (2003). Teaching English pronunciation skills to the Asian learner. A cultural complexity or subsumed piece of cake? Asian EFL Journal, June. Retrieved on 14 October, 2004, from http://www.asian-efl-journal.com/june2003subpr.html

19. Stock, P. (1986). Writing across the curriculum. Theory into Practice. 25 (2): 97-101

20. Wu David, D. (2019). Future Proof: Reinventing work in the age of acceleration. Retrieved from https://dianawudavid.com > wp-content > uploads $>2019 / 01>$ Future_Proof_Insider__Learning_Log_Instructions.pdf

\section{Appendices}

Appendix A

Pre-Post Test: Phonology Concepts

(Score /10)

A. Answer each of the following questions in a short paragrah.

1. Is there a high correspondence between spelling and pronunciation in the English language? Provide examples. (2pts.)

2. Should we teach word and sentence stress in English? Illustrate with examples. (2pts.)

3. Should we teach intonation in English? Illustrate with examples. (2pts.)

B. Transcribe the following into English. (4pts.)

/ bət_aI 'nju:(w)— I _ai wəz 'npt fo' gptn \|

Pænd maI 'feIs | 'nevər_ə'kwaıd I дə 'ho:ntId_ə'kju:zın 'lok ||

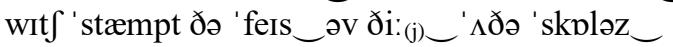

əon 'məust_əv ðə 'ti:tfəz 'tu: \| 
Appendix B

Test 1: Features, physiology and articulation of pronunciation, phonemic transcription, phonology and phonetics

(Score:

/100)

I. In each blank space provided, write the letter of the word that fits from the list. (9 points)

$$
\begin{aligned}
& \text { intonation- minimal set - pure vowel - Segments - correspond } \\
& \text { vowel sounds - allophone - voiced - phoneme - bilabial } \\
& \text { supra-segmental features - unvoiced - syllable }
\end{aligned}
$$

1. The smallest unit of sound is called a

2. Stress, intonation, and connected speed sound changes are known as

3. The way in which the pitch of the voice goes up and down in the course of an utterance is the

4. $\quad \mathrm{P}$ and $\mathrm{m}$ are called sounds.

5. Phonemes are also known as

6. The letters $\boldsymbol{a}, \boldsymbol{e}, \boldsymbol{i}, \boldsymbol{o}$, and $\boldsymbol{u}$ are

7. The sound of $v$ is

8. The $/ \mathrm{r} /$ might cause differences in articulation, but it does not change the meaning of the word.

9. In English language, pronunciation does not with spelling.

II. Read carefully, and then circle the correct choice. (6 points)

1. What differentiates the vowel sounds is

a. The change of position of the tongue inside the mouth, the shape of the lips, and the movement of the lower jaw

b. The change in stress and intonations that affects the tone of the speaker

c. The number of vowels and vowel sounds in the English language

2. Phonology or the sound system of a language involves the study of

a. Phonemes, syllabication, intonation patterns, and rhythmic patterns

b. The nine syllabication rules

c. The study of all pure vowel sounds as well as the diphthongs

3. The ------ letters form ------ sounds; ------ are vowels and ------ are consonants.

a. $26 ; 24 ; 20 ; 44$

b. $26 ; 44 ; 20 ; 24$

c. $26 ; 44 ; 24 ; 20$ 
III. Tell whether the following statements about teaching pronunciation are true or false. Correct the false ones.

(5 points)

1. Pronunciation errors inhibit successful communication and cause problems in reception or comprehension of meaning.

2. Having a one-to-one relationship in L1 between spelling and pronunciation causes difficulties in learning L2 if this second language does not have this relationship.

3. Teachers should not always check the pronunciation of new words in any lesson before they enter to the classroom.

4. / $\mathrm{c} /$ in camel is hard and / $\mathrm{g} /$ in gist is hard.

5. Fortis applies to voiced consonant sounds, while lenis describes unvoiced sounds.

IV. Write the phonemic transcription of these words. (8 points)

\begin{tabular}{|l|l|l|}
\hline 1 & sure & \\
\hline 2 & fetch & \\
\hline 3 & sky & \\
\hline 4 & octopus & \\
\hline 5 & first & \\
\hline 6 & ostrich & \\
\hline 7 & turtles & \\
\hline 8 & sing & \\
\hline
\end{tabular}

I. Write the words that are transcribed. (7 points)

\begin{tabular}{|c|l|l|}
\hline 1 & $/$ di:mæ/ & \\
\hline 2 & $/$ wedzIz/ & \\
\hline 3 & $/$ / $\Lambda \mathrm{s} /$ & \\
\hline 4 & $/$ Ored/ & \\
\hline 5. & $/$ tå:təs/ & \\
& & \\
6. & & \\
\hline
\end{tabular}

\section{J. Answer in short paragraphs. Give examples. (15pts.)}

1. voiced and unvoiced sounds

2. manner of articulation and place of articulation 
3. phonetics and phonology

\section{Appendix C}

Test 2: Approaches, reasons, problems, and techniques for teaching pronunciation pronunciation lesson plan

(Score:

/100)

1.To teach the correct pronunciation of words with soft and hard c, prepare a lesson plan with two activities or techniques in which you teach these two patterns. (60pts.)

2. What problems might face you while teaching the pronunciation lesson you have just prepared and what approach might you follow? (40pts.)

Appendix D

Test 3: Phonemic transcription and English orthography

(Score: /100)

\section{A.Transcribe the following extracts. (50pts.)}

In recent years, some countries have started to use biometric passports. A biometric passport contains a computer chip. As well as personal information, this chip has information about the person's appearance. This can be a digital image of the person's face, of their eyes and their fingerprint. Biometric passports are safer because only the correct person can use the passport. Harvie grew strong and healthy. He had his father's ears and his mother's open heart. But soon his parents began to notice... peculiarities. He began to have odd twitches and liked to touch things with his index finger for no reason at all. When he met someone, he had to touch them on the nose. The doctor said he had Tourette Syndrome, a brain disorder that meant he couldn't control his impulses. It was like trying to control the sneeze. There was no cure or explanation.

\section{B.Write the following passages in normal English orthography. (50 points)}

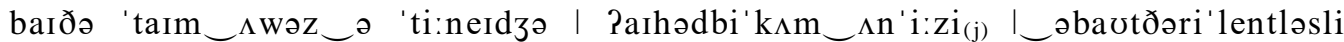

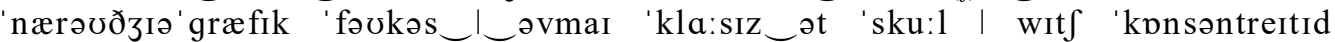
'səolli $(\mathrm{j})$ pn 'westən 'juərəp_ənðəju'naitid 'steits_l_on left 'məust_əvðə

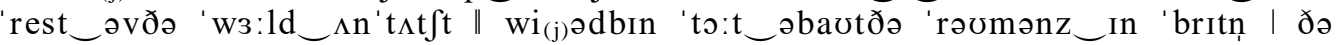
'nə:mən 'west_əv 'tensıksti 'sıks \|

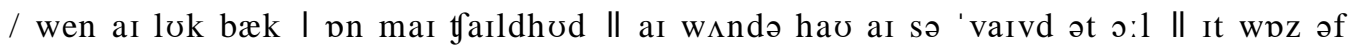

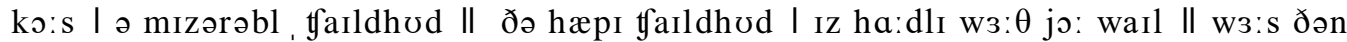

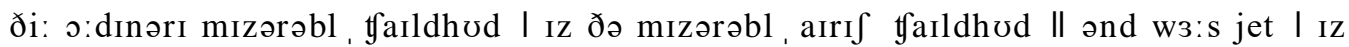

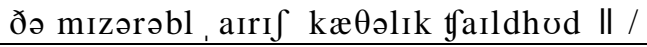




\section{Appendix E}

Test 4: Intonation, word and sentence stress, connected speech, and phonemic transcription (Score: /100)

Part One: Phonetics and Phonology Concepts

$60 / 100$

A. Circle the correct answer. (7 points)

1- In the example "I attended a good concert last night", /d/ assimilates to

$\begin{array}{lll}\text { a. } / \mathrm{d} / & \text { b. } / \mathrm{g} / & \mathrm{c} / \mathrm{p} /\end{array}$

2- In the example, "Who is this man?", a is introduced to ease the transition to a following vowel sound.
a. $/ y /$
b. /u:/
c. /w/

3- When $/ \mathrm{r} /$ phoneme is not pronounced as in $/ \mathrm{ka}: /$, the accent is known as
a-rhotic
b- juncture
c- non-rhotic

4- $\quad$ The term refers to the way the voice goes up and down in pitch when we are speaking.
a- linking / j/
b- intrusive / $\mathrm{r} /$
c- intonation

$5-$ can fall on the first, middle or last syllable of the word.

a- stress

b- phonemes c- consonants

6- The vowel sound in the word / fu:l/ is most likely similar to a- book. b-stood c-fruit

7-The schwa is only used in the a-middle

$$
\text { b- last }
$$
syllable of any English word.

B. Define the following terms and provide examples on each. (15 points): 1-contractions:

\section{2-diphthongs:}

\section{3-elision:}

\section{4-tonic-syllable:}

\section{5-diagraph:}


C. State briefly the two meanings of the italicized phrases by placing the stresses that show different meaning. (20 points)

1. They are encouraging reports.

2. We enjoy frightening visitors.

D. Choose a word from the box to complete each of the following. (8 points)

unstressed - final letter $e$ - first-end- tonic syllable - schwa - suffixes - /b/ - / $k / \quad$ assimilation - $/ p /-\quad$ correspond

1- In order for one syllable to be perceived as stressed, the syllables around it need to be

2- _ is the most commonly occurring sound in English.

3- The is the most stressed syllable in utterance.

4- Schwa exists in most___ such as tion in expectation.

5- In English Language, spelling does not____ or agree with pronunciation.

6- The addition of the changes the sound from a short to a long one or to a diphthong.

7- $\quad$ The $w h$ sound appears everywhere in the word except at the

8- In the example "Jeff is a fat boy", /t/ assimilates to

E. 1. It is known that there is no one-to-one relationship between pronunciation and spelling in English. Suggest two ways teachers can follow to minimize the influence of the spelling/pronunciation confusion. (6 pts) 


\section{State two advantages of teaching pronunciation in FL classes. (4pts.)}

\section{Part Two: Phonemic Transcription}

40/100

\section{A. Write the following passage in normal English orthography. (20 points)}

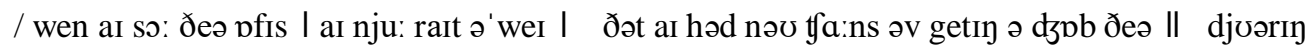

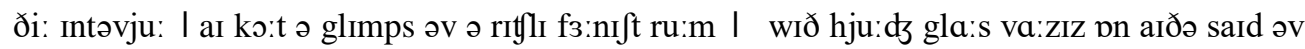
ðə wə:1 II ar ka:nt I' mædə̧ı ðeId wont mi: pn ðeə ti:m /

B. Transcribe the following extract from A Quake of Death. (20 points)

In the world of science, extreme effort is exerted by the scientists to keep the world from the devastation that results from disasters. One of the most destroying catastrophes is an earthquake. In fact, Indonesia's earthquake caused severe damage and injuries that led to the death of hundreds and which urged many relief operations to take action and rescue the situation. 